Jpn. J. Med. Sci. Biol., 51, 43-51, 1998

Epidemiological Report

\title{
TREND OF ADENOVIRUS TYPE 7 INFECTION, AN EMERGING DISEASE IN JAPAN
}

A report of the National Epidemiological Surveillance of Infectious Agents in Japan *

Shizuko YAMADERA, Kazuyo YAMASHITA, Masae AKATSUKA, Nobuko KATO and Sakae INOUYE

National Institute of Infectious Diseases, Infectious Disease Surveillance Center, Toyama 1-23-1, Shinjuku-ku, Tokyo 162-8640

(Received September 16, 1998. Accepted September 26, 1998)

SUMMARY: The program of the National Epidemiological Surveillance of Infectious Diseases under the auspices of the Ministry of Health and Welfare started in 1981 apprehended in 1995 emergence of adenovirus type 7 in Japan. We analyzed the reported data of type 7 comparing with those of type 3 , both belonging to the same subgenus B, and the following results were obtained:

After 1981, the main serotypes in the reports of adenovirus isolation/ detection were types 3,2 , and 1 in this order. The reports of isolation of

\section{Footnotes}

* About 2,800 sentinel clinics of pediatrics, internal medicine, and ophthalmology in the whole country report to health centers weekly incidence of 18 kinds of acute infectious diseases based on clinical diagnoses. About one-third of the sentinel clinics submit specimens taken from patients to prefectural and municipal public health institutes (PHIs) (there are about 70 PHIs in the whole country). PHIs electronically report isolation/detection of each etiological agent mentioned on individual cards together with clinical data to the Infectious Disease Surveillance Center, the National Institute of Infectious Diseases. About 30 institutes are conducting isolation and identification of adenovirus type 7. 
adenovirus type 7 used to be extremely few, however, suddenly increased in 1995. In 1997, reports of isolation of adenovirus type 3 decreased and those of type 7 acquired the third place after those of types 2 and 3. Type 7 infection occur almost every month, but most frequently during MaySeptember. The ages of cases from which type 7 was isolated were 0-4 years accounting for 55\%, 5-9 years $35 \%$, teens $6.3 \%$ and adults $4.0 \%$, being similar proportions to those yielding type 3 .

Clinical diagnoses of cases yielding adenovirus type 7 were pharyngoconjunctival fever (PCF) and influenza-like illness, these two accounting for half. The symptoms were severe, being characterized by higher maximum body temperature during the feverish period and severe pneumonia. Encephalitis and arthro-muscular pain were seen in only type 7-infected cases, although such cases were few.

\section{INTRODUCTION}

Human adenoviruses at present involve 47 serotypes (1). In Japan, 19 serotypes have been isolated since the start of the program of the National Epidemiological Surveillance of Infectious Diseases in 1981; most frequently isolated were type 3 followed by types 2 , 1, and 4 . Type 7 had seldom been detected only in limited areas until 1995(2), when it increased suddenly and was isolated in all over the country in 1997.

It is admitted that adenovirus type 7 causes severe respiratory tract infection including pneumonia among children and acute respiratory tract and eye infections among adults (1). Beside, outbreaks have occurred in the army and boarding schools in many other countries $(6,12)$. Fatal cases among infants, outbreaks in schools and dormitories and nosocomial infection have also been reported in Japan (3), where attention is being paid to type 7 as one of re-emerging viruses.

In the present investigation, analyzed were reported data on isolation of adenovirus type 7 in comparison with those of type 3, belonging to the same subgenus B and evoking similar symptoms, conducted under the program of the National Epidemiological Surveillance of Infectious Diseases.

\section{RESULTS}

Yearly isolation of adenovirus type 7 and the trend of serotypes of adenoviruses isolated

Adenovirus type 7 used to be isolated only sporadically in Akita, Kyoto, Kanagawa, Nagano, Aichi, Nara, and Fukuoka Prefectures until 1994, but since 1995 it has been spread to almost the whole country. Isolation of adenovirus type 7 during 1981-1997 is shown in Fig 1. During 


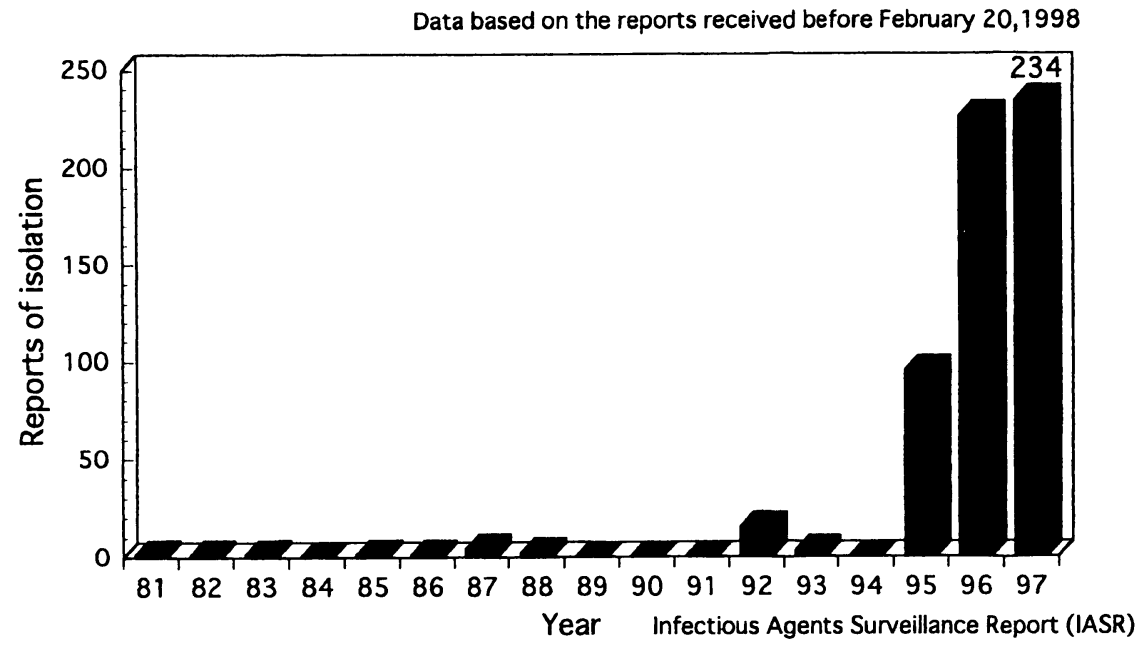

Fig. 1. Yearly isolation of adenovirus type 7 (1981-1997)

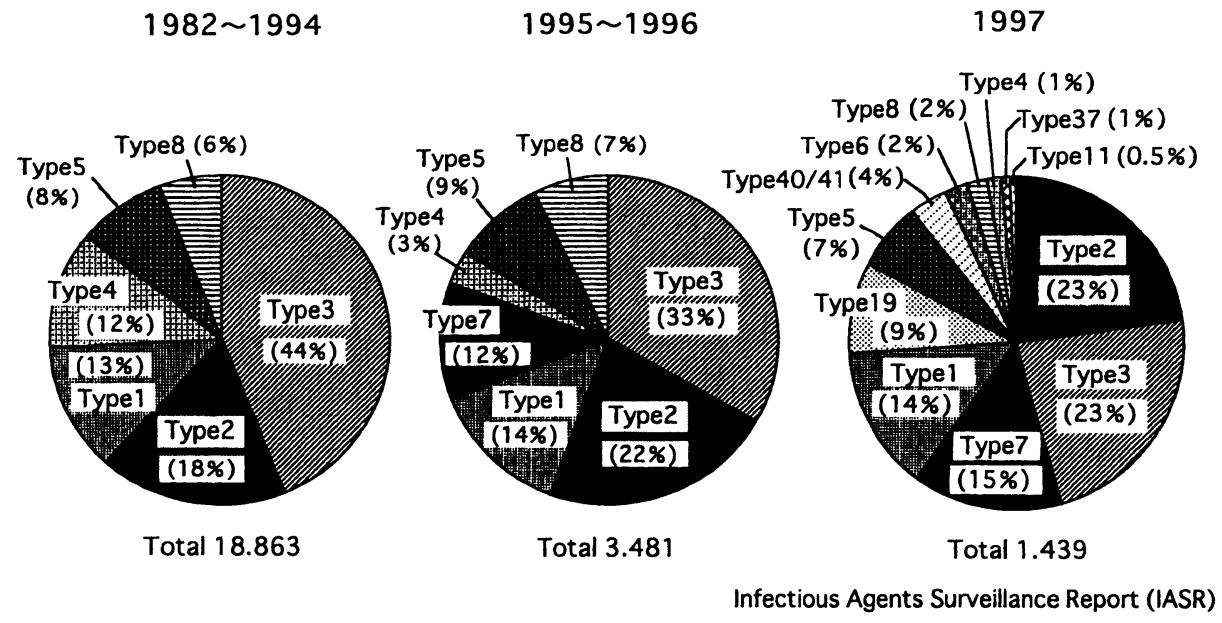

Fig. 2. Proportions of individual serotypes of adenoviruses isolated (1982-1997)

1981-1994, reports of isolation of type 7 were very few, one to four a year, except in 1992 when such reports counted 15, but suddenly increased in 1995, in which year reports of isolation numbered 104. In 1996, reports of isolation of type 7 numbered 220 and, in 1997, 234, and tend to further increase in number.

Fig. 2 shows the trend of yearly isolation of different serotypes of adenoviruses. From 1982 to 1994, reports of isolation of type 3 numbered the largest accounting for $44 \%$, followed by those of type 2 (18\%), type $1(13 \%)$ and type $4(12 \%)$. From 1995 to 1996, reports of isolation involved those of type $3(33 \%)$, type $2(22 \%)$, and type $1(14 \%)$; those 


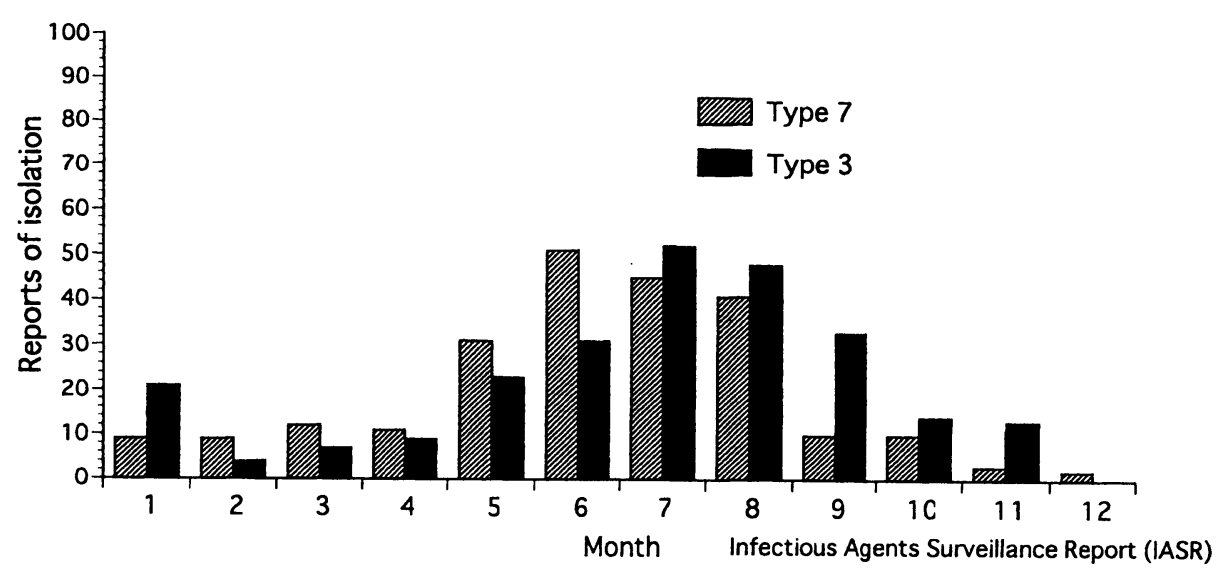

Fig. 3. Monthly reports of isolation of adenoviruses type 3 and type 7 (1997)

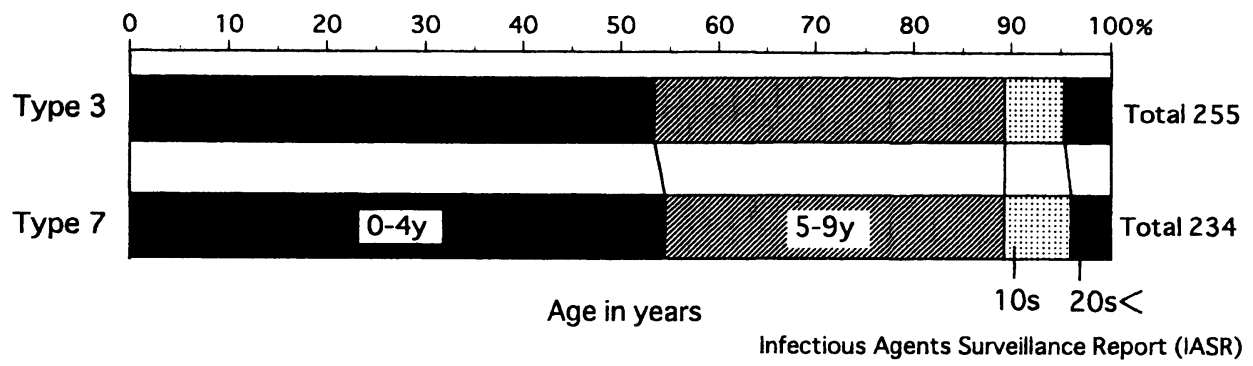

Fig. 4. Age distribution of cases of adenovirus type 3 and type 7 infections (1997)

of type 3 slightly decreased, but the order was unchanged. In 1997, however, reports of isolation of type 3 decreased and those of type 7 increased, the order being those of type $2(23 \%)$, type $3(23 \%)$, and type $7(15 \%)$, and the ratios of the serotypes markedly changed.

Seasonal variation in the frequency of adenovirus type 7 isolation

Fig. 3 shows the numbers of monthly reports of isolation of adenovirus type 3 and type 7 in 1997. Type 7 was isolated almost every month; type 3 was isolated most often during July-September, whereas type 7 during May-September.

\section{Age distribution of type 3- and 7-infected cases}

Age distributions of type 3-infected cases and type 7-infected cases are shown in Fig 4. The type 7-infected cases at the ages of 0-4 years accounted for $56 \%$, followed by those at the ages of $5-9$ years $35 \%$. Those of teens accounted for $7.0 \%$ and those over $20 \mathrm{~s} 4.0 \%$. Nearly the 
Table I . Clinical diagnoses of cases of adenovirus type 7 infection (1997)

\begin{tabular}{lrl}
\multicolumn{1}{c}{ CLINICAL DIAGNOSIS } & \multicolumn{2}{c}{ Number (\%) } \\
\hline PHARYNGO-CONJUNCTIVAL FEVER & $57(27 \%)$ \\
INFLUENZA-LIKE ILLNESS & $32(15 \%)$ \\
INFECTIOUS GASTROENTERITIS & $26(12 \%)$ \\
ATYPICAL PNEUMONIA & $7(3 \%)$ \\
EPIDEMIC KERATOCONJUNCTIVITIS & $7(3 \%)$ \\
ASEPTIC MENINGITIS & $6(2 \%)$ \\
HERPANGINA & $4(2 \%)$ \\
ENCEPHALITIS & $3(1 \%)$ \\
ENCEPHALOPATHY & $2(0.9 \%)$ \\
OTHERS & $70(33 \%)$ \\
\hline TOTAL & $214(100 \%)$
\end{tabular}

Infectious Agents Surveillance Report (IASR)

same tendency was seen with type 3-infected cases.

\section{Clinical diagnoses and conditions of patients}

Clinical diagnoses of patients from which type 7 was isolated were most often PCF, accounting for $27 \%$ of the total diagnoses. Influenza-like illness, infectious gastroenteritis, and pneumonia followed in this order (Table I ).

Each individual card of a case often contained more than two clinical symptoms. Type 7- and type 3-infected cases were compared with respect to all the symptoms but fever (Fig. 5a). Lower respiratory tract infection and gastroenteritis were more often recorded for type 7-infected cases than for type 3-infected ones. Encephalitis and arthro-muscular pain were also recorded for type 7-infected cases. The maximum body temperatures of type 7- and type 3- infected cases were compared (Fig. 5b). In type-7 infected cases, extraordinarily high fever was recorded: fever higher than $40 \mathrm{C}$ was recorded in $49 \%$ and of $41 \mathrm{C}$ in $2.4 \%$ of all patients. In contrast, the maximum body temperature of $40 \mathrm{C}$ or above accounted for $39 \%$ of the type 3 -infected patients.

Reports of isolation of adenovirus type 7 from specimens of different sources

Table II shows isolation of type 7 from specimens of different sources. The specimens from which type 7 was most frequently isolated were pharyngeal swabs accounting for $80 \%$, followed by stool specimens $10 \%$, 


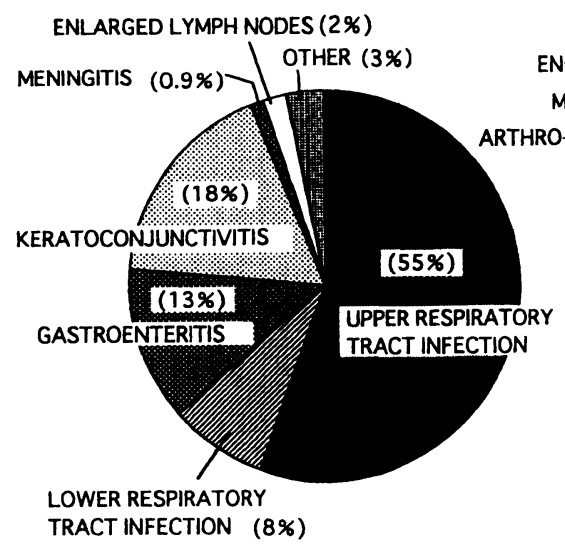

Type 3
ENLARGED LYMPH NODES (2\%)

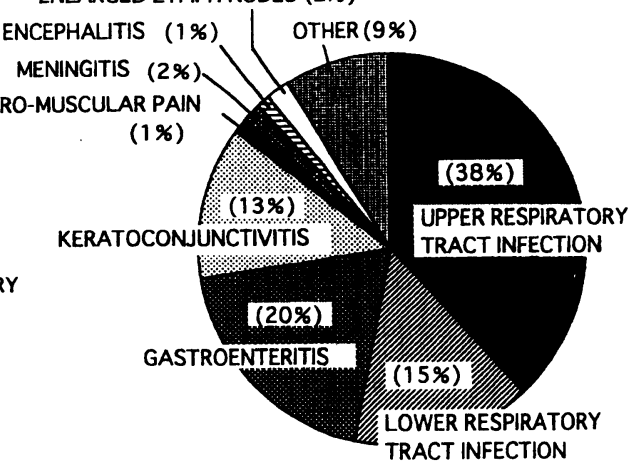

Type 7

Infectious Agents Surveillance Report (IASR)

Fig. 5a. Clinical symptoms of adenovirus type 3 and type 7 infections (excluding fever) (1997)

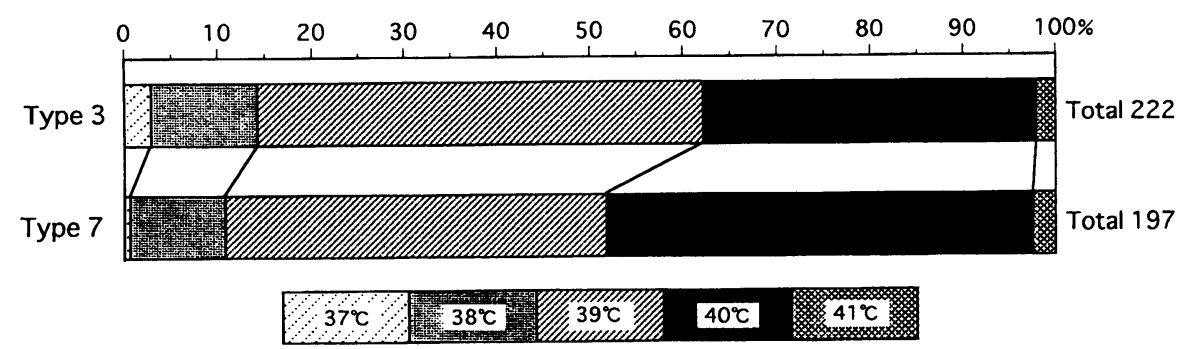

Infectious Agents Surveillance Report (IASR)

Fig. $5 \mathrm{~b}$. The maximum body temperatures of patients of adenovirus type 3 and type 7 infections (1997)

Table II. Specimens for isolation of adenovirus type 7 (1997)

\begin{tabular}{|l|r|}
\hline \multicolumn{1}{|c|}{ SPECIMEN } & \multicolumn{1}{|c|}{ Number $(\%)$} \\
\hline NASOPHARYNGEAL SWAB & $185(73 \%)$ \\
FECES & $44(17 \%)$ \\
EYE SWAB & $18(7 \%)$ \\
LUNG/BRONCH & $2(0.7 \%)$ \\
URINE & $2(0.7 \%)$ \\
OTHERS & $2(0.7 \%)$ \\
\hline TOTAL & $253(100 \%)$ \\
\hline
\end{tabular}

Infectious Agents Surveillance Report (IASR) 
eye swabs $6.7 \%$, lung and bronchial specimens $1.4 \%$, and urine specimens $1.1 \%$.

\section{Epidemic patterns of adenovirus type 3 and type 7 infections}

Outbreaks of type 7 infection occurred in nursery schools, kindergartens, primary schools, hospitals, and families and the reports of isolation from epidemic cases accounted for 24\% (234) of all the reports. The corresponding figure of type 3 infection was $20 \%$ (255). In contrast, reports of isolation of type 2 numbered the largest (549) in 1997, of which those from epidemic cases accounted for only $0.4 \%$ of the total reports and the corresponding figure for type 1-infected cases (362) was $0.6 \%$ (type 1 and type 2 belong to the same subgenus $\mathrm{C}$ ).

\section{DISCUSSION}

The trends of adenovirus 7 infection were compared between Japan and other countries; in Japan it appeared in 1995 as a re-emerging virus, while it is commonly seen in such neighboring countries as China, Korea, and Taiwan $(4,5,6)$. During the period from October 1958 to February 1959, a large epidemic of pneumonia due to type 3 and 7 infections occurred among children in Beijing, and 528 of the 3,398 hospitalized children died (4). In Korea, reports of isolation of type 7, causing acute hemorrhagic urocystitis and gastroenteritis accounted for 10\% of all theadenovirus isolation reports during the half-decade from 1990 to 1994 (6). In Taiwan, adenoviruses isolated from acute respiratory tract infections prevailing among newly enlisted soldiers were reported to be type 7 and type 5 (6). In Australia, type 7 accounted for $17 \%$ of all the adenovirus isolates (7). According to some recent reports, type 7 is a principal serotype of adenoviruses isolated from AIDS patients in the United States (8). Thus, type 7 is a more common virus in other countries than it is in Japan. In Japan, on the other hand, adenovirus type 7 settled down only recently in 1995 .

The seasonal variation of adenovirus type 7 infection in Japan indicates a high prevalence in May-September. In the United States, epidemics of type 7 infection have occurred mainly in summer (9). In the United Kingdom, a large-scale epidemic occurred during 1973-1974 involving 1,132 cases, and additional 518 cases occurred also during 1977-1978 and 496 cases during 1980-1981. These incidents occurred in the summer season (10).

The reports of isolation of type 7 from outbreaks cases accounted for $43 \%$ of all the reports in 1997 in Japan, by far higher proportions than those of types 1 and 2, indicating a high infectivity of type 7. Epidemics 
of type 7 infection have long been recorded in China, the United States, and the United Kingdom $(4,9,10)$.

The cases of type 7 infection most often aged $0-4$ years $(55 \%)$, followed by $5-9$ years $(35 \%)$, in Japan. In the United Kingdom, cases aged 5 years or less were the largest in number and those aged 45 years or more were very few in $1983(10)$. In Germany, cases aged 1-4 years numbered the largest during 1967-1976 (11).

The clinical symptoms were mainly upper and lower respiratory tract infections, gastroenteritis and keratoconjunctivitis; encephalitis and arthro-muscular pain were also recognized. Those with the maximum fever higher than $40 \mathrm{C}$ accounted for more than half of all patients, indicating severer illness than that of type 3 infection. The fatality rates of children from pneumonia caused by type 7 and 3 infections during the period from the winter of 1960 to the spring of 1964 in China were $13 \%$ and $24 \%$ due to types 3 and 7, respectively. The fatality rate of type 7 infection appeared to be higher than that of type 3 infection (4). In the United Kingdom, the clinical symptoms frequently seen were conjunctivitis in adults and respiratory tract infection in children. There were some death cases due to superinfection with measles virus and adenovirus type 7 (12). In Germany, the fatality rate of type 7 infection was high: among 249 death cases of adenovirus infection, 54 were from adenovirus 7 infection (11).

In Japan, no epidemics of type 7 infection had occurred before 1995 and the rate of antibody possession among common people is low. This may have caused the recent spread of adenovirus 7 infection to all over the country (13). When those who have some basal illness are infected with adenovirus type 7 , they tend to develop severe illness. So, adequate countermeasures must be taken to prevent nosocomial spread of infection with type 7 virus that has a high infectivity.

\section{ACKNOWLEDGEMENTS}

We thank the staffs of the prefectural and municipal public health institutes, national hospitals and commercial diagnostic laboratories concerned for supporting the program of the National Epidemiological Surveillance of Infectious Diseases and continuously reporting isolation/ detection of viruses, and to those who gave us valuable advises and suggestions.

\section{REFERENCES}

1. White, D.O. and Fenner, F.(1944): Adenoviridae. Chapter 19, p.306-313. Medical Virology (2nd ed.), Academic Press, New York. 
2. Yamadera, S., Yamashita, K., Akatsuka, M., Kato, N., Hashido, M., Inouye, S. and Yamazaki, S.(1995): Adenovirus Surveillance, 1982-1993. Jpn. J. Med. Scl. Biol., 48, 199-210.

3. Watanabe, Y., Ozawa, S., Machida, T. and Yakutai, K.(1996): Outbreaks of acute respiratory disease due to Adenovirus type 7. Infectious Agents Surveillance Report, Vol. 17, No. 5, p.3, p.6.

4. Li, Q-G., Zehng, Z-J., Liu, Y-H. and Wadell, G.(1996): Molecular epidemiology of adenovirus type 3 and 7 isolated from children with pneumonia in Beijing. Med. Virol., 49, 170-177.

5. Yun, B-Y., Kim, M-R., Park, J-Y., Choi, E-H., Lee, H-J. and Yun, C-K. (1995): Viral etiology and epidemiology of acute lower respiratory tract infections in Korean children. Pediatr. Infect. Dis. J., 14, 1054-1059.

6. Tai, F.H., Grayston, J.T., Johnston, P.B. and Woolridge, R.L.(1960): Adenovirus infections in Chinese army recruits on Taiwan. J. Infect. Dis., 107, 160-164.

7. Curran, C.(1995): Annual report of CDI virology and serology reporting schem, 1994. Comm. Dis. Intellig., 19, 590-615.

8. Hierholzer, J.C., Wigand, R., Anderson, L.J., Adrian, T. and Gold, J.W.M.(1988): Adenoviruses from patients with AIDS: a plethora of serotypes and a description of five new serotypes of subgenus D (types 4347). J. Infect. Dis., 158, 804-813.

9. Fox, J.P., Hall, C.E. and Gooney, M.K.(1997): The seattle virus watch. VII. Observations of adenovirus infections. Am. J. Epidemiol., 105, 362-386.

10. Adenovirus type 7 surveillance (1984): Commun. Dis. Rep., No.23, p.4, 8th June.

11. Schmitz, H., Wigand, R. and Heinrich, W.(1983): Worldwide epidemiology of human adenovirus infections. Am. J. Epidemiol., 117, 455-466.

12. Adenovirus type 7 (1974): Wkly Epidem. Rec., Nos. 11-15, p. 92, March.

13. Nishio, O., Matui, K., Akiyama, M., Matsunaga, Y. and Inouye, S.(1998): Change in antibody prevalence to adenovirus type 7 during the past 20 years in Japan. 39th Clinical Virology Conference. 